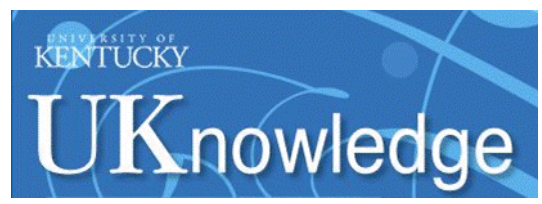

University of Kentucky

UKnowledge

\title{
$2-2014$
}

\section{A Review of the Global Literature on Dental Therapists}

David A. Nash

University of Kentucky, danash@uky.edu

Jay W. Friedman

Kavita R. Mathu-Muju

University of British Columbia, Canada

Peter G. Robinson

University of Sheffield, UK

Julie Satur

Universty of Melbourne, Australia

See next page for additional authors

Follow this and additional works at: https://uknowledge.uky.edu/ohs_facpub

Part of the Dentistry Commons

Right click to open a feedback form in a new tab to let us know how this document benefits you.

\section{Repository Citation}

Nash, David A.; Friedman, Jay W.; Mathu-Muju, Kavita R.; Robinson, Peter G.; Satur, Julie; Moffat, Susan; Kardos, Rosemary; Lo, Edward C. M.; Wong, Anthony H. H.; Jaafar, Nasruddin; van den Heuvel, Jos; Phantumvanit, Prathip; Chu, Eu Oy; Naidu, Rahul; Naidoo, Lesley; McKenzie, Irving; and Fernando, Eshani, "A Review of the Global Literature on Dental Therapists" (2014). Oral Health Science Faculty Publications. 7. https://uknowledge.uky.edu/ohs_facpub/7

This Article is brought to you for free and open access by the Oral Health Science at UKnowledge. It has been accepted for inclusion in Oral Health Science Faculty Publications by an authorized administrator of UKnowledge. For more information, please contact UKnowledge@lsv.uky.edu. 


\title{
A Review of the Global Literature on Dental Therapists
}

\author{
Digital Object Identifier (DOI)
}

http://dx.doi.org/10.1111/cdoe.12052

\section{Notes/Citation Information}

Published in Community Dentistry and Oral Epidemiology, v. 42, no. 1, p. 1-10.

(c) 2013 John Wiley \& Sons A/S. Published by John Wiley \& Sons Ltd

This is the peer reviewed version of the following article: Nash DA, Friedman JW, Mathu-Muju KR, Robinson PG, Satur J, Moffat S, Kardos R, Lo EC, Wong AH, Jaafar N, van den Heuvel J, Phantumvanit P, Chu EO, Naidu R, Naidoo L, McKenzie I, Fernando E. (2014), A Review of the Global Literature on Dental Therapists. Community Dentistry and Oral Epidemiology, 42: 1-10, which has been published in final form at http://dx.doi.org/10.1111/cdoe.12052. This article may be used for non-commercial purposes in accordance with Wiley Terms and Conditions for Self-Archiving.

\section{Authors}

David A. Nash, Jay W. Friedman, Kavita R. Mathu-Muju, Peter G. Robinson, Julie Satur, Susan Moffat, Rosemary Kardos, Edward C. M. Lo, Anthony H. H. Wong, Nasruddin Jaafar, Jos van den Heuvel, Prathip Phantumvanit, Eu Oy Chu, Rahul Naidu, Lesley Naidoo, Irving McKenzie, and Eshani Fernando 
This is the peer reviewed version of the following article: Nash DA, Friedman JW, Mathu-Muju KR, Robinson PG, Satur J, Moffat S, Kardos R, Lo EC, Wong AH, Jaafar N, van den Heuvel J, Phantumvanit P, Chu EO, Naidu R, Naidoo L, McKenzie I, Fernando E. (2014), A Review of the Global Literature on Dental Therapists. Community Dentistry and Oral Epidemiology, 42: 1-10, which has been published in final form at http://dx.doi.org/10.1111/cdoe.12052. This article may be used for non-commercial purposes in accordance with Wiley Terms and Conditions for Self-Archiving. 


\section{A Review of the Global Literature on Dental Therapists}

David A. Nash, University of Kentucky, Lexington, Kentucky Jay W. Friedman, Public Health Dental Consultant, Los Angeles, California

Kavita R. Mathu-Muju, University of British Columbia, Vancouver, British Columbia, Canada

Peter G. Robinson, University of Sheffield, Sheffield, United Kingdom Julie Satur, University of Melbourne, Melbourne, Australia Susan Moffat, University of Otago, Dunedin, New Zealand Rosemary Kardos, University of Otago, Dunedin, New Zealand Edward C.M. Lo, University of Hong Kong, Hong Kong, China Anthony H.H. Wong, University of Hong Kong, Hong Kong, China Nasruddin Jaafar, University of Malaya, Kuala Lumpur, Malaysia Jos van den Heuvel, Dutch Chief Dental Officer (formerly), Amsterdam, The Netherlands Prathip Phantumvanit, Thammasat University, Patumthani, Thailand Eu Oy Chu, Singapore School Dental Service, Singapore Rahul Naidu, University of West Indies, Trinidad and Tobago Lesley Naidoo, Dental Therapy Association of South Africa, Pinetown, KwaZulu-Natal, South Africa Irving McKenzie, University of Technology, Kingston, Jamaica Eshani Fernando, Sri Lanka Dental Association, Colombo, Sri Lanka

Running Title: Global Literature Review of Dental Therapists

Key Words: Dental Therapists, Oral Health Workforce, Access to Care Corresponding Author: David A. Nash, College of Dentistry, University of Kentucky, Lexington, Kentucky; 859.323.2026; Fax: 859.323.4685; danash@email.uky.edu 


\begin{abstract}
Objective: Access to adequate oral health care is deficient in many parts of the world. Many countries are now using dental therapists to increase access, particularly for children. To inform the discussion on dental therapists in the workforce, particularly in the United States, the W.K. Kellogg Foundation funded a review of the global literature to identify as many documents as possible related to the practice of dental therapists since the establishment of the School Dental Service in New Zealand in 1921.
\end{abstract}

Methods: Consultants in each of the countries considered to have a substantive literature on dental therapists were asked to participate in the research; seventeen in total. In addition to identifying and reviewing published articles, a focus of the research was on identifying "gray" documents. Standard data bases were searched for key words associated with dental therapists. In addition, searches were conducted of the governmental and dental association websites of all countries known to have dental therapists in their oral health workforce.

Results: Fifty-four countries, both developing and developed, were identified where dental therapists are members of the workforce. Eleven hundred documents were identified from 26 of these countries, with over $2 / 3$ of them cited in the published monograph. Reliable evidence from the related literature and verbal communication 
confirmed the utilization of dental therapists in an additional 28 countries. Thirtythree of the countries were members of the Commonwealth of Nations, suggesting a mechanism of spread from New Zealand.

Variable lengths of training/education existed for dental therapists with the tradition being two years post-secondary. In a few countries the training of therapists and hygienists is now being combined in a three academic year program. Historically, dental therapists have been employed by government agencies caring for children, typically in school-based programs. Initiatives in some countries have expanded limited care for adults by dental therapists with additional training.

Conclusions: The evidence indicates that dental therapists provide effective, quality, and safe care for children in an economical manner, and are generally accepted by both the public and the dental profession. 


\section{Introduction}

Access to adequate oral health care is deficient in many parts of the world. Many countries are now utilizing dental therapists to increase access, particularly for children. Oral health is poor for many Americans; with barriers to accessing care creating significant oral health disparities among America's children.(1-4) In addressing this issue, efforts have focused on the inadequacy of the oral health care workforce, with calls for expanding the workforce in the United States of America to include the development and deployment of individuals with skills in caring for children traditionally associated with the school dental nurse/dental therapist in New Zealand and many other countries. $(5,6)$ A dental therapist is a "limited" practitioner who can provide basic dental care in the same manner as a dentist. $(7,8)$ Historically, the focus of a dental therapist has been on the prevention and treatment of dental disease in children; however, in some countries they may provide care to adolescents and adults.(9-21)

Worldwide, the scope of a dental therapist's practice generally includes: examination, diagnosis and treatment planning; exposing and interpreting radiographs; oral health education; preventive services such as prophylaxis, fluoride therapy, fissure sealants and dietary counseling; preparation of cavities in primary and permanent teeth and restoration with amalgam and composite; preformed 
stainless steel crowns; pulpotomies; and the extraction of primary teeth.(9) In some countries they may also extract permanent teeth.(22-24)

The introduction of dental therapists to the oral health care team in the United States is controversial.(25-28) Some of the controversy relates to an inadequate understanding of the utilization of dental therapists internationally as members of the dental team. To inform the discussion on dental therapists in the workforce, particularly in the United States, the W.K. Kellogg Foundation funded a review of the global literature to identify as many documents as possible related to the practice of dental therapists since the establishment of the School Dental Service in New Zealand in 1921. This article summarizes, for the referred literature, the extensive literature-based review of the history and practice of dental therapists throughout the world. The complete review of 460 pages was made available at the W.K. Kellogg Foundation website.(29)

\section{Methods}

Consultants in each of the countries considered to have a substantive literature on dental therapists were asked to participate in the research; seventeen in total. They were all knowledgeable academics/public health officials in their respective countries with a history of having dealt with the issue of the dental workforce. In addition to reviewing published articles, a focus of the research was on identifying 
"gray" documents, that is, reports of governmental and non-governmental organizations (NGOs), which addressed the practice of dental therapists, but were not in the academic literature. In addition to obtaining copies of the documents, consultants also translated those that were in languages other than English and prepared written summaries.

The following data bases were searched: ISI Science Citation Index; ISI Social Science Citation Index; Clinical Controlled Trials Register, Cochrane Library; Cumulative Index to Nursing and Allied Health Literature; Database of Abstracts of Reviews of Effects (DARE); System of Indexing Grey Literature in Europe (SIGLE); Medline; Pub Med. Google Scholar and the Google search engine were also searched. Key words searched were "dental nurse," "school dental nurse," "dental therapist,, "school dental service" "school dental therapist," "school-based dental care," "dental auxiliaries," and "dental workforce." In addition, searches were conducted of the governmental and dental association websites of all countries known to have dental therapists in their oral health workforce.

The focus of this research was to identify and annotate the available world literature related to the use of dental therapists in the oral health workforce. No attempt was made to conduct a "systematic" review of the literature. 


\section{Results}

Eleven hundred $(1,100)$ documents were identified that directly or indirectly related to the utilization of dental therapists in the global oral health workforce, and were included in the bibliography of the W.K. Kellogg report; two-thirds of these documents were cited in the body of the document.(29) Themes identified in the literature were: history and distribution of dental therapists; education/training; legislation, registration and licensure; scope of practice and practice settings; oversight, supervision, and safety of care; access to and effectiveness of care; quality of technical care; perspectives of the dental profession; and perspectives of the public.(29) These are summarized in the sections that follow:

\section{History and Distribution of Dental Therapists}

The utilization of dental therapists in the global oral health workforce began in New Zealand in 1921.(30-31) Subsequently, other countries, lacking an adequate oral health workforce, followed New Zealand's lead.

The research identified 54 countries where dental therapists currently are utilized, most often in school-based programs for children. Literature was identified from 26 of these countries: Anguilla, Australia, Bahamas, Botswana, Brunei, Canada, Fiji, Guyana, Hong Kong, Jamaica, Malaysia, Netherlands, New Zealand, Papua New Guinea, Samoa, Seychelles, Singapore, South Africa, Sri Lanka, Suriname, Tanzania, Thailand, Trinidad and Tobago, United Kingdom, United States, and Zimbabwe.(29) 
No documents were able to be identified for the other 28 countries. However, there is reliable evidence, that dental therapists practice in 16 of these 28 other countries. They are Barbados, Cook Islands, American Samoa, Federated States of Micronesia, Granada, Kiribati, Marshall Islands, Nepal, Palau-Belau, Solomon Islands, Tokelau, Tonga, Vanuatu, Vietnam, and Northern Mariana Islands. There is anecdotal evidence that dental therapists practice in the other 12: Belize, Benin, Burkina Faso, Costa Rica, Gabon, Gambia, Laos, Mali, Malawi, Myanmar, Togo, and Swaziland. Early adopters of the dental therapists include: Malaysia (1948),(15) Sri Lanka (1949),(32) Singapore (1950),(33) Tanzania (1955),(23) and the United Kingdom (1959)(34). Additional countries added dental therapists to their oral health workforce later, including Australia (1966),(35) Thailand (1968),936) Jamaica (1970),(17) Canada (1972),(11) Fiji (1973),(37) Trinidad and Tobago (1975),(38) Seychelles (1974),(21) South Africa (1975).(22) Suriname (1976),(39) Hong Kong (1978).(40)

The utilization of dental therapists is more common in countries that were members of the British Commonwealth. Of the 54 countries employing dental therapists, 33 are members of the Commonwealth of Nations.(29)

In the United States, the Alaska Native Tribal Health Consortium introduced dental therapists to care for Alaska Natives in tribal villages in 2005.(41-43) In 2009, the 
state of Minnesota authorized the training and practice of dental therapists to care for underserved segments of its population, with the first dental therapists entering practice in 2011. $(44,45)$

Dental therapists are utilized in both developed and developing countries. Five of the top six countries of the world on the Human Development Index employ dental therapists in their oral health workforce, at least to some extent: Australia (2), Netherlands (3), United States (4), New Zealand (5), and Canada (6). Other countries employing dental therapists in the top 50 countries of the Index are: Hong Kong (13); Singapore (26); United Kingdom (28); Brunei (33), and Barbados (47)(29).

\section{The Training/Education of Dental Therapists}

New Zealand pioneered the development of dental therapists, with the first class of 29 school dental nurses graduating from a two year post-high school vocational training program in Wellington, New Zealand in 1923.(30) They were trained to provide dental care for primary school children, and were deployed to serve in a public School Dental Service.

Vocational training in a 2-3 year curriculum is the norm in most countries utilizing dental therapists, with the awarding of a certificate or diploma on completion. In some countries, the training/education of dental therapists has moved to university 
settings, sometimes in combination with the dental hygienists, with curricula of $2 \frac{1}{4}-$ 3 years in length; though in one country the curriculum is of 4 years duration. $(9,46-$ 48)

Gaining knowledge of the basic biomedical sciences supporting dental practice and the acquisition of perceptual motor skills tend to be the focus of the initial period of curricula, with intense clinical training taking place subsequently. A strong emphasis on community oral health promotion and disease prevention exists in the curricula.

The training/education programs of some countries present opportunities for dental therapists that include dual training/education as dental therapists/dental hygienists, as well as graduate degree education. $(8,49,50)$ Continuing education modules and/or formal education programs are available in some countries, enabling dental therapists to add skills to their scope of practice. $(9,51)$

\section{Legis/ation, Registration, and Licensure}

The legislation relating to the current attempt to add dental therapists to the workforce in the United States is pertinent to this review. In 1949, legislation directed the Massachusetts Department of Public Health to provide dental hygienists two years of training after which they would be permitted to prepare and fill cavities in children's teeth under the supervision of a dentist.(52) Under pressure of the dental associations, the law was rescinded a year later.(53) Again in the 
1970s, authorization was provided for the "Forsyth Experiment," which successfully trained dental hygienists to provide basic dental services. However, under pressure from dentists, the program was terminated before its conclusion.(54)

In 2003, the Alaska Native Tribal Health Consortium (ANTHC) sent Native American Alaskans to New Zealand to train to become dental therapists. $(41,42)$ They returned to be employed as Dental Health Aide Therapists (DHATs). The American and Alaska Dental Associations sued the ANTHC, and the individual DHATs for the illegal practice of dentistry, but the suit was withdrawn once the Alaska attorney general ruled that the DHATs were practicing under federal legislation, thus not subject to state law.(55) Supervising dentists establish the DHAT's scope of practice by documenting in "standing orders" those services they can perform under indirect and general supervision.(56)

In 2009, the Minnesota state legislature authorized the creation of two categories of dental therapists, a dental therapist (DT), and an advanced dental therapist (ADT). As the legislation was passed to enhance access to care, DTs and ADTs are only permitted to practice in settings serving low-income and underserved populations.(44) 
Literature on legislation, registration, and licensure of dental therapists is sparse for most countries. Since most countries limit dental therapists to governmental service, they are not necessarily licensed or registered. Their scope of practice regulates their provision of care, with responsibility for supervision and review designated to their respective ministries of health.

Legislation, registration, and licensure vary from country to country. National, state, or provincial legislation authorizes the practice of dental therapists. Regulation is generally by Dental Councils (Dental Boards). In the many countries where dental therapists are public employees in school dental services, they are certified and regulated directly by the government's ministry of health, or their employing service. In a few countries where more autonomy for practice is granted, dental therapists are licensed as professional practitioners just as are dentists.

\section{Practice Settings and Scopes of Practice}

In many countries, the setting for the practice of dental therapists has expanded from school-based clinics to community-based health centers, hospital clinics, and mobile dental units. However, the service has continued to focus on caring for school children, though not exclusively, as care is provided to adults in some countries.(22-24, 47, 57-59) Dental therapists in some jurisdictions are permitted to work in private practices. 
The following countries utilize dental therapists as public employees serving children in a school dental service: New Zealand; Australia; Hong Kong; Singapore; Malaysia; Jamaica; Trinidad and Tobago; Bahamas; Anguilla; Papua New Guinea; Sri Lanka; Seychelles; Brunei Darussalam; Guyana; Samoa; Suriname, and the United Kingdom.(29) In the several countries for which literature was not able to be obtained, it was reported that dental therapists also function primarily in caring for school children. In these countries, the dental therapist's scope of practice is similar and includes basic procedures for providing primary preventive and restorative care for children as indicated previously.

While dental therapists' scope of practice typically is restricted to children, an increasing number of countries permit dental therapists, frequently with additional training, to treat adults as well. In New Zealand and Australia dually qualified dental hygienists/dental therapists may provide dental therapists' treatments to children and adolescents, and dental hygiene care for adults. Dental therapists may provide care to adults if the therapist is educated and registered in that scope of practice.(60) 


\section{Oversight, Supervision, and Safety of Care}

The literature on dental therapists emphasizes their oversight and supervision by dentists to protect the public. As the majority of dental therapists work with children in public school-based programs, supervision is by a government dentist, who may or may not be on site. Dental therapists adhere to standing orders and policy frameworks that define their scope of practice, which are determined by the government service in which they work.

Levels of supervision vary among countries, and in different settings within the same country. In some countries dental therapists may practice independently without dentist supervision; and in others independently, but with a collaborative/consultative relationship with a dentist.

The literature did not reveal any issues of safety or harm as a result of care provided by dental therapists.(29)

\section{Quality of Technical Care}

There have been many evaluations of the technical quality of care provided by dental therapists over the past 60 years. The studies have consistently found that the quality of technical care provided by dental therapists (within their scope of 
competency) was comparable to that of a dentist, and in some studies was judged superior.(61-78)

The continued utilization of dental therapists in the 54 countries identified provides tacit documentation of an acceptable quality of technical care provided by dental therapists.

\section{Access to Care and Effectiveness of Care}

The impetus for adopting dental therapists as part of the oral health workforce has typically been to improve both access to care and effectiveness of care for children.

Studies from countries where dental therapists are public health employees of school dental programs demonstrate the positive impact of this delivery model upon the effectiveness of care for children, especially in reducing the amount of untreated decay. Studies show high enrollment in school dental programs over time, and reveal their positive influence in improving access to care for large numbers of children, often the entire population of elementary school children.

Evaluations of dental services based on the oral health of the population must take into account falling levels of dental caries due to other factors, such as fluoridation, and the many factors that mediate the relationship between service provision and 
population health. However, the proportion of dental caries in children that has been effectively treated can be considered a proxy indicator of the accessibility and effectiveness of dental care.

For example, in 1964 in New Zealand, 72\% of all the elementary school children's teeth affected by dental caries had been restored. The equivalent figure for the United States was 23\%.(79) The average number of untreated decayed teeth per 1519 year old in New Zealand fell from 3.2 in 1962 to 1.3 in 1976.(80) Findings of a 2009 oral health survey by the Ministry of Health found that $81.7 \%$ of the teeth requiring care had been treated. (81)

Again in New Zealand in 2010, over 60\% of children, aged 2-4, were enrolled in and utilized the publicly funded child oral health services; $98 \%$ of $5-13$ year olds were enrolled.(81) As 2003 data indicate, essentially all carious teeth of the elementary school children had been restored or extracted (primary teeth) at the end of a school year.(82) Using 1988-1994 data, the percentage of carious primary teeth, through age 14 , that had been restored in the U.S. was $63.3 \%$; for the permanent teeth it was $74 \%$. The percentages dropped to $48.7 \%$ for primary teeth for children at $100 \%$ of the federal poverty level; and $72.3 \%$ of permanent teeth of children in that socioeconomic group.(83) One study reported that only $22 \%$ of all children in the United States six years of age or younger had received any dental care.(84) 
Repeated evaluations show very high utilization rates of similar school dental services elsewhere including $80 \%$ of Saskatchewan schoolchildren before the program was terminated;(85) 95\% of primary schoolchildren in Hong Kong;(86) and $96 \%$ of elementary and $67 \%$ of secondary school children in Malaysia.(87) Children from lower socio-economic groups are more likely to benefit from school dental programs staffed with dental therapists.

A number of reports indicate the economic value of dental therapist-led school dental services. The school dental programs in New Zealand and Australia cost less than private fee-for-service systems for the same service.(88-91) For example, the average cost of school-based dental care in New Zealand is \$99 (U.S.)/child.(92) In the private sector in New Zealand an examination, radiographs and cleaning alone would be similarly priced; and a simple restoration would cost an additional \$99; a fissure sealant $\$ 47 .(92)$

Recent data from Hong Kong indicate that the average cost of care for the 315,000 children participating in the school dental service was approximately $\$ 78 /$ year (US).

The opportunity for more economical care is related, in part, to the salary differential between dental therapists and dentists. An average New Zealand therapist earns $\$ 30-45,000$ (U.S.); whereas, the average private practicing dentist earns $\$ 120,000-\$ 150,000 /$ year (U.S.).(88) 
Data from the Saskatchewan program in Canada, indicated that the cost of treating a child fell over $271 \%$, from $\$ 341.89$ in private practice in 1974 to $\$ 91.98$ in 1986 in the school dental service.(93) In a 2011 report, Canadian Center for Policy Alternatives analyzed the financing of the Saskatchewan school-based program of the 1980 s that included $85 \%$ of 5-14 year olds in the province. The report concluded that if the program existed throughout Canada today, the inflation adjusted cost for comprehensive preventive and restorative care would be $\$ 176.25 / \mathrm{child}$. As a comparison, a general dentist's fee in the private sector today is approximately $\$ 225$ for a pulpotomy and stainless steel crown. Such a public, school-based program utilizing dental therapists for treating all of Canada's 5-14 year olds would cost $\$ 560$ million, representing a dramatic savings in expenditures.(94)

\section{Perspectives of the Dental Profession toward Dental Therapists}

The perspective of the dental profession is well represented in the literature on dental therapists. A comprehensive range of views is evident, but in general these views polarize into opponents and proponents. In some cases, the intellectual quality and tone of the debate has reflected poorly on the dental profession.

Many dentists and professional dental associations in the United States are opposed to the inclusion of dental therapists on the dental team. $(25-27,95)$ They have 
asserted dental therapists threaten the health and safety of the public by providing a lower quality of care, and that they open a wedge for unqualified individuals to practice dentistry. Dental therapists have been described variously as a hazard and "a menace to the public, a menace to the [dental] profession, and an injustice to those seeking to enter the ranks of the profession."(96)

Proponents of dental therapists refute these assertions and accuse the opponents of having a hidden agenda, particularly of looking after their own economic interests.(97-99) They cite a study that has shown that dentists, despite not knowing who dental therapists are or what they do, oppose them anyway.(100)

Proponents note that dental therapists' care has been evaluated on numerous occasions and in multiple countries. They argue that they provide high quality, safe and effective care equal to that of dentists working under the same conditions; and do so at a lower cost. Dental therapists included on the dental team are thought to liberate dentists' for more complex treatment. They also argue that services employing dental therapists extend the geographical reach of dentistry, increase access to care, and provide a safety net for those who cannot otherwise obtain care. Proponents equate the use of dental therapists with the utilization of 'mid-level providers,' such as nurse practitioners, who function effectively in other areas of health care. 
Both proponents and opponents of dental therapists have attributed views to the general public, often in the absence of evidence. Proponents claim that "patients-both adults and children-of every socioeconomic stratum will find care delivered by dental therapists to be entirely acceptable."(101) Opponents have argued that they would not be accepted by the public, and might be resented by individuals in lower socio-economic groups as providing second class, inferior care.(64)

The dental profession in the countries reviewed, are generally supportive of the role dental therapists play in caring for the oral health of the population, specifically with regard to children.(102-105) To the extent that concern or dissatisfaction could be identified in the literature, it typically related to dental therapists treating adults or practicing independently.(106) The evidence suggests that once dental therapists have been introduced in a country, professional support for them increases over time.

Harold Hillenbrand, the respected Executive Director of the American Dental Association from 1946 to 1970, said: "When the dental history of our time is eventually written, I believe the New Zealand Dental Nurse Program will be considered one of the landmark developments in the practice of dentistry and dental 
public health." He went on to say New Zealand has "pioneered in a very effective method for delivering dental health services to children." Finally, he concluded, "the New Zealand experience proves that we can develop an auxiliary program-and a very advanced one-that is acceptable to and approved by the profession of the country involved."(107)

\section{Perspectives of the Public toward Dental Therapists}

In the United States, philanthropic foundations frequently provide leadership for the public in identifying societal problems and funding pilot projects to stimulate both private and public sectors in resolving them. The problem of access to health care and its negative impact on the health of poor and underserved populations has been a focus of several U.S. foundations in recent years. With respect to oral health issues, these foundations have recognized that dental therapists in the oral health workforce can assist in addressing the problems of access and disparities. They have provided funds for research, advocacy, and implementation of oral health care programs. Among the foundations are: Robert Wood Johnson Foundation; Pew Charitable Trust; Rasmuson Foundation; W.K. Kellogg Foundation; and the Macy Foundation.(29)

The W.K. Kellogg Foundation commissioned a national survey on the views of Americans on the issue of access to dental care. "More than three-quarters of 
respondents (78\%) support an effort to train a new dental provider-a licensed dental practitioner-to work under the supervision of a dentist to provide preventive, routine care to people without regular access to care."(108)

The high level of utilization of school dental services employing dental therapists in a large number of countries is strong evidence they can provide care that is acceptable to and valued by parents, who have to provide consent for their children to enroll and be treated. Numerous and detailed evaluations of these programs, summarized in this literature review, reveal strong patient and parental support for dental therapists.(29)

The people of New Zealand consider the School Dental Service with its dental therapists a New Zealand "icon." Another report states: "The School Dental Service has become an integral component of the New Zealand culture. To Kiwis it is like motherhood, apple pie and the flag."(5)

Parents in Saskatchewan were "outraged" at the termination of the school-based plan and the transfer of the children to the private sector for their dental care.(109) No evidence could be found to indicate that the public perspective of dental therapists in any country was other than positive. 


\section{Conclusions}

The global literature indicates:

1. Dental therapists practice in 54 countries, including highly developed, industrialized ones, as well as developing countries.

2. There are variable lengths of training for dental therapists, from 2 to 4 years, existing in a variety of vocational training/academic environments.

3. Dental therapists typically practice as registered auxiliaries, but in some jurisdictions practice as licensed professionals.

4. Dental therapists practice primarily in public clinics, typically associated with caring for school children.

5. Dental therapists' scope of practice is primarily in caring for children, although several countries permit caring for adults, and others are moving in that direction.

6. Dental therapists typically practice with general supervision by dentists. 
7. Dental therapists provide technically competent care in accordance with their scope of practice.

8. Dental therapists improve access to care, specifically for children.

9. Dental therapists are effective in providing oral health care within their scope of practice.

10. Dental therapists have a record of providing oral health care safely.

11. In general, the dental profession in a country accepts the care provided by dental therapists in its country as valuable.

12. The public values the role of dental therapists in the oral health workforce.

13. There is a movement in a few countries to integrate the training, and therefore scopes of practice, of the dental therapist and dental hygienist.

14. Dental therapists included in the oral health workforce have the potential to decrease the cost of care, specifically for children. 


\section{References}

1. U.S. Department of Health and Human Services. Oral health in America: a report of the surgeon general. Rockville, Maryland: U.S. Department of Health and Human Services, National Institute of Dental and Craniofacial Research, National Institutes of Health, 2000.

2. Dye BA, Tan S, Smith V, et al. Trends in oral health status: United States, 1988-1994 and 1999-2004. Washington, D.C.: National Center for Health Statistics. Vital and Health Statistics, Series 11, Number 248, 2007.

3. Gehshan S, Straw T. Access to oral health services for low income people: policy barriers and opportunities for intervention by the Robert Wood Johnson Foundation. Forum for State Health Policy Leadership, Washington, D.C.: National Conference of State Legislatures, 2002. 25 pages.

4. General Accounting Office (GAO). Oral health: factors contributing to low use of dental services by low-income populations. Washington, DC: General Accounting Office, 2000, 41 pages.

5. Nash D A. Developing a pediatric oral health therapist to help address oral health disparities among children. J Dent Educ 2004 68(1):8-20.

6. Nash D A. Developing and deploying a new member of the dental team: a pediatric oral health therapist. J Pub Health Dent 2005 65(1):48-55.

7. Sanders J L. The New Zealand school dental nurse: comments of recent reports. NZ Dent J 47: April, 1951.

8. Satur J, Moffat S. A history of oral health practice (dental therapy and dental hygiene) in Australia and New Zealand. Chapter 1 in Tsang A KL. Oral health therapy programs in 
Australia and New Zealand: emergence and development. School of Dentistry, University of Queensland, 2010.

9. Tsang AKL, editor. Oral Health Programs in Australia and New Zealand. Varsity Lakes, Queensland, Australia: Knowledge Books and Softwear, 2010. 323 pages.

10. Roder DM. The employment of dental nurses. J Pub Health Dent 1978 38:159-171.

11. Davey KW. Dental therapists in the Canadian north. J Canadian D Assoc 1974 40:287291.

12. Lewis MH. Dental care delivery in Saskatchewan, Canada. In: International Dental Care Delivery Systems. Edited by JI Ingle and P Blair. Cambridge, Massachusetts: Ballinger Publishing Company, 1975.

13. Davies WIR, Corbet EF, Chiu, GKC. Dentistry's development in Hong Kong. Int Dent J 1997 47:137-141.

14. Singapore Health Promotion Board. Oral health care services for primary school. Singapore: National Health Promotion Board, 2009.

15. Malaysia Ministry of Health. Malaysia Dental Training School, Golden Jubilee Book, 50 years, 1949-1999, 1999. Penang, Malaysia.

16. Naidu R, Ramroop V, Rafeek R. An historical overview of dentistry in Trinidad and Tobago. History in Action 1(1):1-10 St. Augustine: University of West Indies, Department of History, 2010.

17. Spohn EE. Consultant's report to the Jamaica Ministry of Health, reviewing the dental nurse and dental assistant training program at the Dental Auxiliary Training School in Kingston. Lexington, Kentucky: College of Dentistry, University of Kentucky, 1966. 
18. Adewakun AA, Amaechi BT. Consistency and conformity in caries assessment among dental nurses in Anguilla, British West Indies. Oral Health and Prev Dent 2003 1(4):273281.

19. Davies, GN. Training oral health personnel. Suva, Fiji: Fiji School of Medicine Mission Report, 1990.

20. Sri Lanka Dental Therapists Training School. Report on the review and development of the curriculum for school dental therapists. Maharagama: Sri Lanka Dental Therapists Training School, 1986.

21. Ernesta K, Dogley MH, Arissol E, Pothin H. The Seychelles dental service. Seychelles Med Dent J. (Special Issue) 2004 7(1):28-35.

22. Hugo J. Mid-level health workers in South Africa: not an easy option. Department of Family Medicine, Medical University of Southern Africa, 2005. 12 pages.

23. Poulsen S, Fubusa F, Gember PM, Lemak PA, Mosha HJ, Ntabaye MK. Distribution of dental therapist and assistant dental officers trained under the Tanzania-Danida dental health programme 1981-1993. Odontostomatologica Tropicale 1999 22(86):19-22.

24. Eriksen HM, Dondon M. Dental therapists in Botswana. Odontostomatologica Tropicale 1983 6(2):69-74.

25. American Dental Association. House of Delegates Proceedings. ADA Annual Session Chicago: American Dental Association, 2004.

26. Hinson P. Mid-level providers are not in the best interest of children. Pediatric Dentistry 2009 31(5):375-376.

27. Georgia Dental Association. White paper on Georgia's oral health status: access to and utilization of oral health care services. Atlanta, Georgia: Georgia Dental Association, 10 pages, 2010. 
28. American Academy of Pediatric Dentistry. Policy on workforce issues and delivery of oral health care services in a dental home. American Academy of Pediatric Dentistry Reference Manual. Ped Dent 2012 33(6):26-30.

29. Nash DA, Friedman JW, Mathu-Muju KR, Robinson PG, Satur J, Moffat S. et al. A Review of the Global Literature on Dental Therapists: In the Context of the Movement to Add Dental Therapists to the Oral Health Workforce in the United States. Battle Creek, Michigan: The W.K. Kellogg Foundation, April 12, 2012. 456 pages. Available at www.wkkf.org/knowledge-center/resources/2012/04Nash-Dental-Therapist-Literature$\underline{\text { Review.aspx }}$

30. Sanders, JL. The New Zealand School Dental Nurse Service: Its initiation and development 1920-1960. Wellington: RE Owen, Government Printer, 1963.

31. Brooking, TWH. A history of dentistry in New Zealand. Dunedin: New Zealand Dental Association, 1980.

32. New Zealand School Dental Service Gazette. Ceylon women dental surgeon will study. New Zealand School Dental Service Gazette 1953 XIII (1):3.

33. Singapore Ministry of Health. Dentistry in Singapore: 1819-1996. Singapore: Singapore Ministry of Health. 87 pages, 1996.

34. Nuffield Foundation. An inquiry into dental education: a report to the Nuffield Foundation. London: The Nuffield Institute, 1980.

35. Roder, DM. The school dental therapist of South Australia. J Pub Health Dent 1972 32(2):70-82.

36. Laddawan, NMR. History of the school dental nurse. Directory of Dental Nurses. Chonburi Institute of Public Health, 1967. 
37. Daunivalu S. Organizational structure for the Fiji dental service. A thesis for the diploma in public health dentistry. Sydney: University of Sydney, 1992.

38. Atwell R. [Thesis] A plan to develop the dental services of Trinidad and Tobago. Faculty of Dentistry, University of Toronto, 1972.

39. Guile EE, Hagens E, De Miranda JC. Dental nursing in Suriname: training and development. J Dent Educ 1981 45(3):156-161.

40. Wong SPY. Training and utilization of dental therapists in the School Dental Care Service. J Hong Kong Soc Comm Med 1981 12:17-20.

41. Nash DA, Nagel RA. Brief history and current status of the dental therapy initiative in the United States. J Dent Educ 2005 69(8):857-859.

42. Nash DA, Nagel RJ. Confronting oral health disparities among American Indian/Alaska Native Children: the pediatric oral health therapist. Amer J Pub Health 2005 95(8):13251329.

43. Mathu-Muju KR. Chronicling the dental therapist movement in the United States. J Pub Health Dent 2011 71:278-288.

44. State of Minnesota. Revised Statutes, 150A.105, 150A.106. St Paul: State of Minnesota, 2009.

45. Glasrud P, Embertson C, Day T, Dercks A. History of Minnesota's therapist legislation: or... what the heck happened up there. Minneapolis: Minnesota Dental Association. 32 pages, 2009.

46. Rowbotham JS, Godson JH, Williams SA. Csikar JI, Bradley S. Dental therapy in the United Kingdom: part 1. Developments in therapists' training and role. Brit Dent J 2009 207:355-359. 
47. General Dental Council. Scope of practice [all dental personnel]. London: General Dental Council. 12 pages, 2009.

48. Singapore Dental Council. Register as an oral health therapist. Singapore: Singapore Dental Council, 2008.

49. Van Den Heuvel J. Oral health care professions in the Netherlands. In The U.S. Oral Health Workforce in the Coming Decade: Workshop Summary. Institute of Medicine, National Academies. Washington, D.C.: National Academies Press. 160 pages, 2009.

50. Singapore Ministry of Health. Information sheet on dental therapists in the Singapore Dental Service. Singapore: Singapore Ministry of Health. 3 pages, 2007.

51. General Dental Council/ Dental therapy and hygiene programmes and qualifications. London: General Dental Council, 2011.

52. American Dental Association House of Delegates action on dental nurses program questioned by Massachusetts Commissioner of Health. J Amer Dent Assoc 1950 40:363366.

53. American Dental Association. Massachusetts dental nurse bill rescinded. J Amer Dent Assoc 1950 41:371.

54. Lobene RR. The Forsyth experiment: an alternative system for dental care. Cambridge, Massachusetts: Harvard University Press, 1979.

55. Anchorage Daily News, Alaska lawsuit dropped. July 12, 2007.

56. Williard ME, Fauteux N. Dentists provide effective supervision of Alaska's dental health aide therapists in a variety of settings. J Pub Health Dent 2011 71 S2:S27-S33.

57. American Dental Hygienists' Association. Report of the people to people ambassador programs/delegation to South Africa. Chicago: American Dental Hygienists' Association. 39 pages, 2009. 
58. Singapore Dental Council. Register as an oral health therapist. Singapore: Singapore Dental Council, 2008.

59. Van Den Heuvel J, Jongbloed-Zoet C, Eaton K. The new style dental hygienist changing oral health care professions in the Netherlands. J Dent Health 44(6): 3-10, 2005.

60. Moffat SM, Coates DE, Meldrum AM. New Zealand's changing oral health workforce. A dental practitioner's guide to dual-trained dental therapists/dental hygienists. $N$ Z Dent J 2009 105(2):57-61.

61. Fulton JT. Experiment in dental care: results of New Zealand's use of school dental nurses. Monograph Series 4. Geneva, Switzerland: World Health Organization, 1951.

62. General Dental Council Final Report on the Experimental Scheme for the Training and Employment of Dental Auxiliaries. London: General Dental Council, 1966.

63. Dunning JM. Deployment and control of dental auxiliaries in New Zealand and Australia. J Amer Dent Assoc 1972 85:618-626.

64. Redig D, Dewhirst F, Nevit G, et al. Delivery of dental services in New Zealand and California: a report to the California Dental Association and Southern California Dental Association Dental Education Councils. S Calif Dent Assoc 1973 41(4):318-321.

65. Lobene RR. The Forsyth experiment: an alternative system for dental care. Cambridge, Massachusetts: Harvard University Press, 1979.

66. Spohn EE, Chiswell LR, Davison DD. The University of Kentucky experimental expanded duties dental hygiene project. Lexington: College of Dentistry, University of Kentucky. 54 pages, 1976. 
67. Sisty NL, Henderson WG, Paule CL, Martin JF. Evaluation of student performance in the four-year study of expanded functions for dental hygienists at the University of lowa. J Amer Dent Assoc 1978 97:613-627.

68. Barmes DE. Review of the South Australian School Dental Service. Geneva: World Health Organization, Oral Health Unit, 1983.

69. Arrow P, Riordan PJ. Retention and caries preventive effects of a GIC and a resin-based fissure sealant. Comm Dent Oral Epidem 1995 23(5):282-285.

70. Ambrose ER, Hord AB, Simpson WJA. Quality evaluation of specific dental services provided by Saskatchewan dental plan: final report. Regina, Saskatchewan, 1976.

71. Crawford PR, Holmes BW. An assessment and evaluation of dental treatment in the Baffin Region. Ottawa: Medical Services Branch of National Health and Welfare, 1989.

72. Trueblood, RG. A quality evaluation of specific dental services provided by Canadian dental therapists. Ottawa: Health and Welfare Canada. 15 pages, 1993.

73. Fiset L. A report on quality assessment of primary care provided by dental therapists to Alaska natives, September 30, 2005.

74. Bolin KA. Assessment of treatment provided by dental health aide therapists in Alaska: A pilot study. Journal of the American Dental Association 2008 139:1530-1535.

75. Wetterhall S, Bader JD, Burrus BB, Lee JY, Shugars DA. Evaluation of the Dental Health Aide Therapist Workforce Model in Alaska: Final Report. North Carolina: RTI International, Research Triangle Park, 2010.

76. Bader JD, Lee JY, Shugars DA, Burrus BB, Wetterhall S. Clinical technical performance of dental therapists in Alaska. Journal of the American Dental Association 2011 142:322329. 
77. Calache H, Shaw J, Groves V, Marino, M M, Gussy M, Satur J, Hopcraft M. The capacity of dental therapists to provide direct restorative care to adults. Austra N Z JPub Health 2009 33(5):424-429.

78. Asegali E. A study of re-do restoration at the school dental clinic at SK Pasir Putih Tawau District (Sabah, Malaysia). Penang, Malaysia: Diploma of Dental Nursing Research Report, 2011.

79. Walsh J. International patterns of oral health care-the example of New Zealand. Special supplement on oral health, facts, figures, and philosophy; selected papers from the centennial observances of the Harvard School of Dental Medicine. Harvard Dental Alumni Bulletin 2008: 10-18.

80. Hunter PBV, Davis PB. Oral health care for Canterbury, New Zealand, 13-14 year old students. Int Dent J 1976 26:334-339.

81. New Zealand Ministry of Health Our oral health: key findings of the 2009 New Zealand oral health survey. Wellington: Ministry of Health, 2010.

82. New Zealand National Health Committee. Improving child oral health and reducing child oral health inequalities: report to the Minister from the Public Health Advisory Committee. Wellington, New Zealand: Public Health Advisory Committee. 94 pages, 2003.

83. Kaste LM, Selwitz RH, Oldakowski JA, Brunelle JA, Winn DM, Brown L. Coronal caries in the primary and permanent dentitions of children and adolescents 1-17 years of age (1988-91): United States. J Dent Res 1996 75:631-641.

84. Mouradian WE, Schaad DC, Kim S, Lleggott PJ, Domoto PS, Maier R, et al. Addressing disparities in children's oral health: a dental-medical partnership to train family practice residents. J Dent Educ 2003 67(8):886-895. 
85. Lewis, DW. Performance of the Saskatchewan Health Dental Plan, 1974-1980. Toronto: Faculty of Dentistry, University of Toronto. 84 pages, 1981.

86. Hong Kong Government. Hong Kong 2010, "Health." 156-185 (Dental Health, page 163). Hong Kong: Government Printer, 2011.

87. Malaysia Ministry of Health. Oral health care in Malaysia. Kuala Lumpur, Malaysia: Oral Health Division, Ministry of Health, 2005.

88. Croucher N. A letter from New Zealand: improving access to high quality dental services for children. J Calif Dent Assoc 2011 39(2):83-87.

89. Blaikie DC, Weidenhofer RNG. The cost of school dental care: a preliminary economic analysis. Austral Dent J 1978 23(2):146-151.

90. Milsteed C. [Thesis] The dental industry: costs of anti-competitive behavior. University of Melbourne, 1996.

91. Martin C. Adequacy and availability of dental services in regional, rural and remote Western Australia, Report No. 1; Education and Health Standing Committee, Western Australia Legislative Assembly, Perth, 2002.

92. New Zealand Ministry of Health Internal data. Wellington: New Zealand Ministry of Health, 2012.

93. Rezansoff, S. SHDP: An experiment in success that failed. Saskatchewan Econ J 1997 19.

94. Canadian Center for Policy Alternatives. Putting our money where our mouth is: the future of dental care in Canada. Ottawa: Canadian Center for Policy Alternatives. 44 pages, 2011.

95. Bramson JB, Guay AH. Comments on the proposed pediatric oral health therapist. J Dent Pub Health 2005 65(3):123-127. 
96. Leslie GH. More about dental auxiliaries. Aust Dent J 1971 16(4):201-209.

97. Nash DA. Response to Drs. Bramson and Guay's Comments on the proposed pediatric oral health therapist. J Pub Health Dent 2005 65(3):128-130.

98. Friedman JW. The international dental therapist: history and current status. Calif Dent Assoc J 2011 39(1):23-29.

99. Friedman JW. [Letter] Dental therapists are a positive innovation. Amer J Pub Health 2012 102(3): 390-391.

100. To'olo G, Nash DA. Mathu-Muju KR, Haney CA, Mullins MR, Bush HH. Perspectives of board-certified pediatric dentists on adding a pediatric oral health therapist to the dental team. J Ped Dent 2010 32(7)505-512.

101. Bertolomi C N. Access to care: is there a problem? Amer J Pub Health 101(10):1817.

102. Dolah S, Bar SR, Jaafar N. Evaluation of the school dental nurse system and their role in delivery of oral health care to school children in Malaysia-perceptions of Senior Dental Officers. BDS Research Report. Kuala Lumpur: Faculty of Dentistry, University of Malaya. 56 pages, 2006

103. Khumeungsitti P. The satisfaction of employers of the public health graduates of Sirindhorn College of Public Health, Chonburi: Research report of the Prabaromrajchanok Institute for Health Workforce Development, Thailand Ministry of Health, 2009.

104. McKenzie I. Response to dental therapist survey questionnaire from Nash and Friedman. Lexington: College of Dentistry, University of Kentucky, 2006.

105. Ross MK, Ibbetson RK, Turner S. The acceptability of dually-qualified dental hygienisttherapists to general dental practitioners in South-East Scotland. Brit Dent J 2007 202:E8; discussion 146-147.

106. Thai Dental Council. Patient case study and investigation, 2010. 
107. Hillenbrand $\mathrm{H}$. What can we learn from others? The New Zealand legacy. In: J.I. Ingle, P. Blair, ed. International dental care delivery systems: issues in dental health policies. Proceedings of a colloquium sponsored by the Institute of Medicine and the Pan American Health Organization. Battle Creek Michigan: Ballinger Publishing Co. Published with the support of the WK. Kellogg Foundation, 1978.

108. W.K. Kellogg Foundation. The dental access gap. Lake Research Partners. Battle Creek, Michigan: W.K. Kellogg Foundation. 7 pages, 2011.

109. Niedermayer JW. Socialized dentistry for children in Saskatchewan: its beginning-1974, its demise-1993. J Canad Dent Assoc 1993 59(6):522-524.

This research was conducted with the support of the W.K. Kellogg Foundation, Battle Creek, Michigan. 